\title{
Research and Implementation of the Transformation and Development Path of Applied Undergraduate Universities
}

\author{
Wei Zhang"
}

Xi'an Peihua University, Xi'an 710125, China

*Corresponding author. Email: zhangwei@ peihua.edu.cn

\begin{abstract}
Based on the requirements and characteristics of the cultivation of applied technical talents, this paper studies and explores contemporary advanced educational concepts and teaching methods, finds the practical entry point and design integration point for the transformation and development of applied undergraduate colleges, and innovatively integrates a concept (OBE achievement-oriented concept), 1 standard (CEEAA engineering professional certification), 1 mode (CDIO engineering education mode) and 1 method (WPS work process systemization) forming a distinctive "OCCW" application technology first-class talent training system, It is also the first "point-line-surface-body-net" application course system.
\end{abstract}

Keywords: application-oriented; undergraduate colleges; transformation and development; path research.

\section{REFORM BACKGROUND}

The teaching mode of higher education in China is mainly based on the elite education of research universities. From the design of the curriculum system to the selection of curriculum content to the methods of teaching methods, all infiltrate the induction and memory of the knowledge system and emphasize the theory and practice. [1] With the popularization of higher education from elite education to popular education, most college graduates have migrated from scientific research to applied technology jobs, and major changes have taken place in the work level and work fields. Therefore, The traditional teaching model has been unable to meet the teaching needs of applied technical undergraduate colleges.

The design of the curriculum system for professional personnel training in colleges and universities in China is basically a tree structure based on "knowledge reserve", which is usually composed of four parts: public courses, professional basic courses, professional courses, and practical courses. [2] This course system structure is based on disciplines. The construction of the "old three segments" of the system, focusing on the classification, induction and storage of knowledge, is more suitable for the cultivation of thick-based research talents. For the cultivation of applied talents, a curriculum system based on "knowledge application" is required. This curriculum system not only has certain requirements for students 'theoretical knowledge, but more importantly, it has more obvious training for students' practical ability. There should be an organic connection between the courses. Teachers 'teaching should be based on social needs, take real projects as the carrier, and focus on the integration of knowledge in related fields.
Students do it in school, in middle school, and gradually transform knowledge into skills, and ultimately achieve the purpose of training technical talents. Therefore, it is imperative for universities in transition to develop an applied curriculum system and curriculum reform.

\section{RESEARCH PATH}

\subsection{Build an applied technical talent training system and establish a new model for applied talent training}

According to the requirements and characteristics of the cultivation of applied technical talents, the school researches and explores contemporary advanced educational concepts and teaching methods, finds the practical entry points and design integration points for the transformation and development of applied undergraduate colleges, and innovatively integrates one concept (OBE Achievement-oriented concept), 1 standard (CEEAA engineering professional certification), 1 model (CDIO engineering education model) and 1 method (systematization of WPS work process), [3]forming a distinctive "OCCW" application technology talent The training system solves the problems of difficulty in implementing the transformation and development of colleges and universities, and the vagueness of methods and methods. 


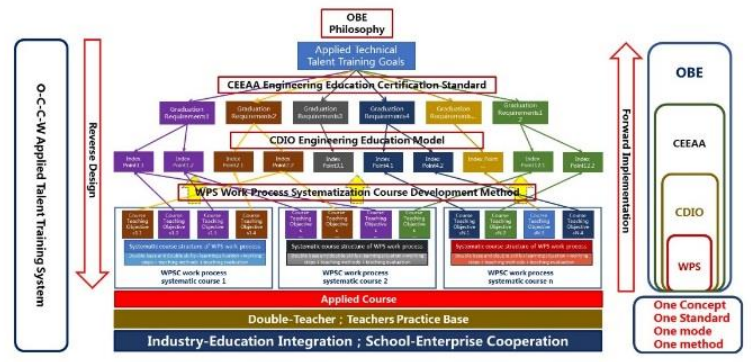

Figure 1 "O.C.C.W" applied technical talent training system

\subsection{Build an application-oriented curriculum system structure model, understand and reconstruct the subject knowledge system}

In order to help teachers realize the in-depth deconstruction and reconstruction of the curriculum structure, the school designs graduation requirement index points according to the application technology talent training goals, and sets up relevant curriculum groups, clarifies the curriculum objectives and curriculum content, and implements the curriculum through the learning situation and the implementation of the task Objectives and graduation requirements are effectively achieved. Pay attention to the combing of the internal relationships of key elements, take knowledge points (points) and skill points (points) as the basic content units of course teaching, effectively integrate knowledge points and skill points to build ability units (lines), and combine ability units to form a learning situation ( Area), superimposed learning contexts constitute course units (body), and related course units form a course system (net) according to graduation requirements, that is, constitute a "point-line-area-body-net" applied course architecture model. as shown in picture 2 .

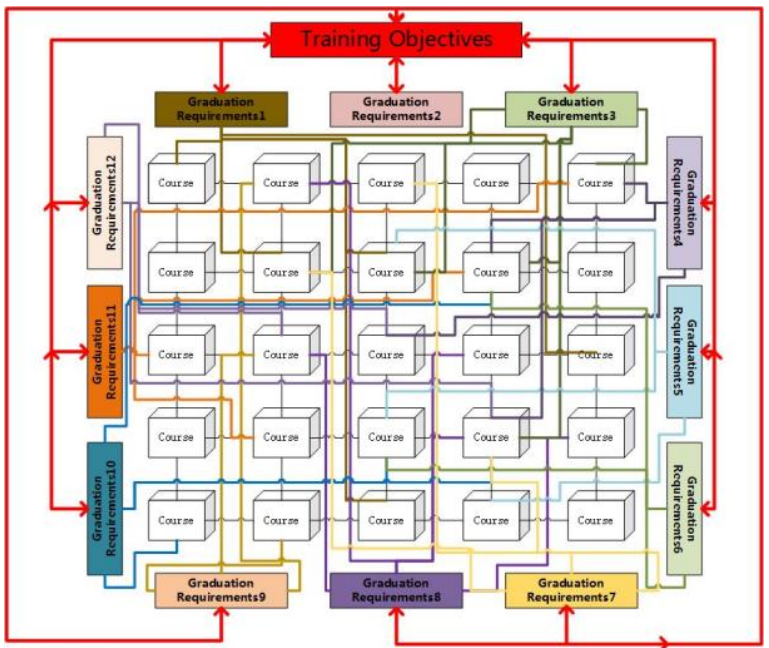

Figure 2 "Point-line-surface-body-net" applied curriculum architecture model

\subsection{Issue policy documents to solve the problem of ambiguous direction of applied curriculum reform}

In order to meet the needs of the school to fully implement the reform of classroom teaching of applied courses and let every teacher master the teaching methods and means of applied courses, the school has formulated the "Guiding Opinions on the Reform of Classroom Teaching of Applied Courses of Xi'an Peihua College" "Xi'an Peihua College "Implementation Opinions on Deepening the Reform of Applied Curriculum", etc., with curriculum positioning, design, implementation, and evaluation as the four elements of reform, to achieve the fit of the curriculum positioning reflects the training goals of service majors, and the curriculum design reflects the "dual base and dual skills" and practical The degree of integration, the implementation of the curriculum reflects the closeness of "teaching, learning and doing", and the curriculum evaluation reflects the performance of the application ability in practice and other goals.

\subsection{Revise the talent training program according to the $O B E$ concept to solve the problem that the curriculum system does not support the training goals enough}

Xi'an Peihua College revises the professional talent training plan according to the applied technical talent training goals and the OBE achievement-oriented concept, builds a curriculum system based on the training goals and graduation requirements, and implements "student center, output-oriented, continuous improvement" The relevant requirements of the $\mathrm{OBE}$ concept and professional certification are integrated into the revision of the training plan, and each major is required to complete the graduation goal of talent training and the weight matrix of the relationship between the curriculum support and the curriculum support, to reflect the basis and characteristics of the training of applied technical talents in each major of the school. Transformational development and talent training positioning provide strong evidence support. According to the professional teaching laws and the inherent logic of the curriculum, the curriculum system is reasonably constructed, with the basic quality and technical application ability training as the main line, the concept of vocational education is strengthened and the integration of general education and vocational education is emphasized. The basic professional courses emphasize "real", and the core professional courses emphasize "Fine" combines the setting of the curriculum system with the actual situation of students, adjusts and optimizes the curriculum structure, and realizes the transformation from "simply imparting knowledge" to "strengthening ability training". For more details, please refer to the "Guiding Opinions on Xi'an Peihua University's Cultivation and Development of Talent Training Program". 


\subsection{Revise the syllabus according to the concept of $O B E$ to solve the problem of low connection between course objectives and training objectives}

The revision of the curriculum syllabus is guided by OBE and the "systematization of work processes" to guide and optimize the structure and content. It incorporates the requirements of "curriculum standards" and can reflect the characteristics and evidence of the cultivation of applied technical talents at the curriculum level. The transformation of teaching from emphasizing the transfer of theoretical knowledge to emphasizing ability training, emphasizing the guiding role of "innovative", "applicable", and "practical" in teaching, while focusing on the education of basic concepts, basic principles, and basic methods, highlights The cultivation of students' innovative spirit, practical ability and comprehensive quality reflects the requirements of professional training objectives and professional characteristics for the curriculum knowledge structure. The deconstruction and reconstruction of the knowledge system is reflected in the revision of the syllabus, actively and steadily promoting the reform of curriculum teaching, and improving the overall level of curriculum construction and professional construction.

\subsection{Design the course structure according to the theory of "systematization of work processes" to solve the problem of the old and solidified course content attached to the subject system}

Traditional courses are usually attached to the subject system, focusing on the accumulation and memory of knowledge. The application of knowledge and technology is not high, and it cannot be adapted to the requirements of the cultivation of applied technical talents. The "systematization of work process" course is based on the design of the situation and the "six-step method", which integrates the knowledge points and skill points in the subject course into the learning situation and work tasks, gradually implements the teaching from simple to complex, and works the teaching tasks. Education, curriculum of work tasks, emphasis on linking theory with practice, and colleges and universities to connect with industry enterprises, so as to solve the problems that students trained in traditional colleges cannot adapt to social and industry requirements.

The "Working Process Systemization" course generally has more than three learning scenarios. The working process of each learning scenario follows the six steps of "consultation, planning, decision-making, implementation, inspection, and evaluation". It has a background in the integration of industry and education and school-enterprise cooperation. Under the circumstances, teachers combine the real environment of the enterprise and the real project design learning situation, master the true skills in the real learning and real work, so as to achieve the "integration of reality" in the course teaching, and fundamentally cultivate the students' theoretical and practical learning and work ability.

\section{CONCLUSION}

In recent years, the employment quality and student learning satisfaction of our college graduates have generally shown an upward trend. In 2018, a total of 3,772 undergraduates graduated from our school, with a graduation rate of $99.65 \%$, a degree-granting rate of $97.96 \%$, an employment rate of $95.11 \%$, and an employment rate higher than the national average employment rate of universities and colleges by $90.30 \%$; the number of graduate students increased from the previous year $21.05 \%$. According to our school's sample survey on student self-learning and growth satisfaction, $93.1 \%$ of students are generally satisfied with undergraduate teaching. Students' overall satisfaction with school-related construction and education, management, and service work is generally good, and they generally believe that their studies in school have met expectations. Through the investigation of the 2016-2018 graduates of our school by Makos, the student's satisfaction with teaching has shown a clear upward trend.

\section{ACKNOWLEDGMENT}

This research was financially supported by the Shaanxi Higher Education Teaching Reform Research Project (Research and Practice on the Construction of Applied Curriculum System in Universities with Transformation and Development, 2019.12-2021.6, project number 19BG034, Shaanxi Provincial Department of Education).

\section{REFERENCES}

[1] He Huanhuan, Liu Hui. Exploration of "Working Process Systematization Model" in the Professional Course Development of Apprenticeship Pilot Program [J]. Science and Technology, 2020 (09): 75.

[2] Chen Guolong. Cognition and Exploration: The Road to the Construction of Entrepreneurial University in Local Undergraduate Universities [J]. Journal of National Education Administration College, 2020 (03): 9-14 + 42.

[3] Jiang Dayuan. The key to curriculum development: structural issues [J]. World Education Information, 2018, 31 (21): 53-54. 